\title{
Estilos de vida y revitalización del espacio urbano
}

\section{Juan Carlos de Pablos Ramírez}

Universidad de Granada. Departamento de Sociología

Rector López Argüeta, 4. 18071 Granada

jdpablos@ugr.es

\section{Ligia Sánchez Tovar}

Universidad de Carabobo (Venezuela)

Universidad de Granada. Departamento de Sociología

Rector López Argüeta, 4. 18071 Granada

ligias@ugr.es

\section{Resumen}

Este trabajo trata de profundizar en los distintos elementos que configuran los estilos de vida, tanto hacia dentro - a través de la búsqueda de la calidad de vida- como hacia fuera, en la configuración del espacio urbano. Está referido a un centro histórico — que además es Patrimonio de la Humanidad: el Albaicín de Granada-, donde el efecto de esta confluencia es la revitalización del mismo, según patrones diferenciados que afectan al modo de entender las relaciones con los distintos elementos que organizan ese espacio, como las relaciones interpersonales, las infraestructuras, el turismo, el papel de la Administración, etc. Se parte de un enfoque cualitativo, orientado a profundizar en la significación de los estilos de vida para los propios residentes, y se proponen algunas posibles repercusiones para la reproducción del espacio urbano, con carácter general.

Palabras clave: estilos de vida, calidad de vida, revitalización urbana, Patrimonio de la Humanidad.

\section{Abstract. Life styles and urban space revitalization}

This piece of research work deals with different elements of life styles, internal (through life quality) and external (towards urban space constitution. It refers to a historical urban centre: the Albaicín of Granada world Heritage. The different elements that organize the space, the interpersonal relations, the role of the Administration, among other factors, are analysed in qualitative terms. So, the importance of life styles for residents and the consequences of the reproduction of the urban space are presented in the article.

Key words: Life Style, Quality of Life, Urban Rentalization, Wold Heritage.

\section{Sumario}

1. Introducción: vivir en el Patrimonio de la Humanidad

2. Los estilos de vida

3. El estudio de la calidad de vida

4. El Albaicín como espacio vital
5. Metodología

6. Resultados

7. Conclusiones

Bibliografía 


\section{Introducción: vivir en el Patrimonio de la Humanidad}

En este trabajo se sondea cómo se percibe, desde los estilos de vida, la relación con el medio social y cultural que supone el barrio - no un barrio cualquiera, sino el Albaicín de Granada, declarado Patrimonio de la Humanidad-en tanto que contexto más inmediato de la vida, y de qué manera esta relación de carácter individual y colectivo se asocia a la búsqueda de calidad de vida. Desde luego, la particularidad de un entorno histórico, con sus peculiares condiciones físicas, ambientales y culturales, aconseja la búsqueda de explicaciones sobre la calidad de vida de sus habitantes desde un enfoque que supere lo estrictamente cuantitativo. El estudio trata, por tanto, de realizar una aproximación cualitativa a la significación que se da a la calidad de vida de acuerdo con el estilo de vida, y cómo dicha significación se podría constituir en un factor impulsor del desarrollo del espacio habitado. El desarrollo de la investigación intenta responder a algunas preguntas clave como:

- ¿Qué papel juega el barrio del Albaicín en la calidad de vida de sus residentes? ¿Y en la configuración de su estilo de vida?

- A la inversa, ¿qué visión tienen los residentes del Albaicín del propio barrio? ¿Cómo se relacionan con los distintos elementos que lo configuran?

- ¿Qué aporta cada uno de los estilos de vida al barrio y de qué manera pueden contribuir los residentes del Albaicín a su revitalización?

Partimos de algunas precisiones teóricas respecto a los estilos de vida y a la calidad de vida, para luego ver el barrio y caracterizar en él los distintos estilos de vida considerados. Posteriormente, a la luz de la información aportada por los participantes en el estudio, identificamos aquellos elementos que permiten dar respuesta a los interrogantes planteados. Consideramos este trabajo una primera aproximación empírica, que no pretende alcanzar conclusiones categóricas, sino desvelar aspectos que, de acuerdo con la percepción de los habitantes del barrio, se asocian a la calidad de vida y que pudieran orientar, más adelante, el desarrollo de investigaciones puntuales.

\section{Los estilos de vida}

El énfasis en la vida cotidiana y la posibilidad de hacer realidad el proceso de diferenciación social como consecuencia de la abundancia de recursos que proporciona la sociedad de consumo ha venido a promover una cierta estilización de la vida, promovida tanto desde las estructuras de mercado como desde los medios de comunicación: la posesión de un estilo de vida ha venido a constituirse un objetivo prioritario, elemento esencial de la composición de la propia identidad personal, objetivo imprescindible en los modernos mecanismos de integración social. Así, Andrés Orizo (1992: 238) planteó cómo el estilo de vida «se forma con la combinación de bienes que uno elige y las actividades que uno hace, todo ello procesado en una configuración más abstracta que 
viene determinada por los valores que se detentan y la ubicación sociocultural que nos distingue».

Por su parte, Giddens (1995: 106) ha definido el estilo de vida como «un conjunto de prácticas más o menos integrado que un individuo adopta no sólo porque satisfacen sus necesidades utilitarias, sino también porque dan forma material a una crónica concreta de la identidad del yo». La cultura tradicional no disponía del amplísimo rango de posibilidades que ofrece la modernidad, pues estaba vinculada a formas usuales de hacer y de vivir exigidas para la supervivencia de la propia sociedad. Sin embargo, las nuevas formas de organización social impelen a las personas concretas a convertir su modo de vida en un auténtico estilo de vida, como expresión de su capacidad individual y de la búsqueda de nuevas formas de comunidad (Maffesoli, 1990). En suma, es lo que Giddens (1995: 26) caracteriza como «un orden postradicional en el que a la cuestión ¿cómo vivir? hay que responder con decisiones tomadas cada día sobre cómo comportarse, qué vestir, qué comer - y muchas otras cosas-; además, tal cuestión se ha de interpretar en el despliegue de la identidad del yo en el tiempo». Es decir, los estilos de vida vienen a proporcionar una respuesta integradora al problema del consumo, entendido como un conjunto de prácticas aisladas, al vincularlo con el concepto de identidad, tal como hace Bocock (1995: 102), cuando plantea que en la sociedad avanzada las personas "crean un sentido de quiénes son a través de lo que consumen».

Los estilos de vida cada vez son menos "transmitidos", como sucedía con los modos de vida propios de la premodernidad. Al contrario, son adoptados, como consecuencia de las prácticas vitales que se hacen consistentes, relativas a los distintos aspectos de la vida cotidiana. La novedad estriba en que es precisamente este ámbito de la vida corriente el que se ha transformado, de manera que las elecciones acerca de los elementos aparentemente más insignificantes «son decisiones referentes no sólo a cómo actuar, sino a quién ser», tal y como señala Giddens (1995: 106). Cuanto más postradicionales sean las circunstancias en que se mueva el individuo, más afectará el estilo de vida al núcleo mismo de la identidad del yo, a su hacerse y rehacerse. Así, Soldevila (1998) ha tipificado idealmente la construcción de un estilo de vida en varias fases: una fase deconstructiva de uno mismo, de repliegue hacia dentro y búsqueda interior; una fase constructiva, caracterizada por la construcción del propio proyecto personal, y una fase de implementación interactivo-comunitaria, es decir, la puesta en práctica del propio estilo de vida: unos valores y fines, unas formas y condiciones de vida que se expresan de manera comunitaria.

Por otra parte, el barrio puede ser el contexto adecuado para la comprensión de los diferentes estilos de vida que en él cohabitan, de acuerdo con los hallazgos de Leonardo Aurtenetxe (1989), que muestra la escasa homogeneidad de la mayoría de las zonas urbanas. Partimos de la consideración que el espacio habitado tiene una significación para cada individuo y cada grupo social, así como que todo barrio posee condiciones particulares que le hacen distinguirse de otros, expresándose en forma de ventajas o privilegios para sus habitantes, y también de inconvenientes, siempre mezclados. 


\section{El estudio de la calidad de vida}

Tras analizar con exhaustividad la calidad de vida, Setién (1993: 137-138) la define como «el grado en que una sociedad posibilita la satisfacción de las necesidades (materiales y no materiales) de los miembros que la componen, capacidad que se manifiesta a través de las condiciones objetivas en que se desenvuelve la vida societal y en el sentimiento subjetivo que de la satisfacción de sus deseos, socialmente influidos, y de su existencia poseen los miembros de una sociedad». Desde luego, es una materia que presenta multitud de enfoques y orientaciones, fruto de la compleja interrelación entre sus dimensiones, entre las que destaca el eje objetivo versus el subjetivo (OCDE, 1982; Campbell, Converse y Rodgers, 1976; Michalos, 1985) y la tensión entre equilibrio (entre logros y aspiraciones) y riqueza intrínseca (Nordenfelt, 1993). Sin embargo, para enmarcar los contenidos de este trabajo, puede ser suficiente destacar que, por debajo de las diferencias electivas, y por encima del grado de bienestar material o nivel de vida, la clave de la calidad de vida se halla en la capacidad de control de las propias condiciones en que se vive; es decir, la posibilidad de decidir cómo, dónde y por qué se vive como se vive: «la disponibilidad, por parte del agente, de recursos y actividades para sacar adelante un programa de vida más allá de la mera razón de supervivencia, es decir, del sentido instrumental del trabajo y las actividades cotidianas como medio de subsistencia» (De Pablos, Pascual y Gómez, 1999: 68).

Este planteamiento coincide con la perspectiva adoptada por Nussbaum y Sen (1996), para quienes la complejidad del tema obliga a tratarlo no sólo desde lo que materialmente se tiene o se carece, sino que es necesario considerar, además, lo capaces que son los individuos de conducir sus vidas, requiriéndose una descripción densa, minuciosa y compleja respecto a lo que las personas pueden hacer y ser. En términos de Sen (1995: 9), es preciso incorporar al análisis aspectos relativos a la "capacidad de conseguir aquellos "funcionamientos" valiosos que componen nuestra vida, y más generalmente de conseguir nuestra libertad de fomentar los fines que valoramos». La calidad de vida se vuelve entonces total (no se dice calidad de trabajo o de vivienda, sino de vida) y posee un sentido estratégico que involucra tanto la actuación como la reflexión, conformándose al medio natural y al ambiente socio-cultural. Por tanto, el logro de la calidad de vida no depende exclusivamente de los individuos, sino que implica también al colectivo. Podríamos preguntarnos entonces de qué manera perseguir la calidad de vida favorece la organización y la participación ciudadana en beneficio de proyectos de desarrollo que no sólo responden a intereses individuales, sino que pueden estar articulados a intereses colectivos.

Además de estudiar la calidad de vida como estado (la calidad que se posee en una situación dada, con la puesta en juego de los propios recursos para realizar determinadas actividades), hemos de considerar un sentido dinámico de la misma, la calidad de vida como proceso (De Pablos, Gómez y Pascual, 1999), que no es sino un mecanismo de interacción continua entre los agentes y la sociedad, un conjunto de tensiones orientadas a lograr aquello que todavía 
falta por conseguir en el proyecto personal (Giddens, 1995), que conducen a los individuos a apostar por una determinada opción: es el campo de actuación para hacer real lo posible, aceptando lo necesario, lo que tiene que ser asi y lo que puede ser de otra manera en el contexto social en que se vive. Es la dimensión individual de la «sociedad del riesgo" (Beck, 2001), que será de especial relevancia a la hora de considerar el Albaicín como el entorno adecuado para vivir. Como resultado de una situación diferencial por parte de los distintos agentes y grupos sociales (Bourdieu, 1991), estas tensiones se plantearán y se resolverán diferenciadamente, según dos modos principales:

1. Un modo materialista (en honor a Inglehart), propio de quienes poseen recursos escasos y para quienes la calidad - goce, elección- se alcanza cuando una parte se destaca en el todo de la vida, proporcionándose satisfacciones que no se disfrutan de manera frecuente ni continuada. No obstante, esto no quiere que no haya pequeños o grandes placeres en la vida, sino que el carácter instrumental — la supervivencia— domina las actividades que se realizan: el sentido del ocio es el descanso, reponer fuerzas para continuar trabajando. Es el modo propio de las sociedades tradicionales menos ricas, donde la finalidad es reunir recursos para la realización de determinadas actividades. En este grupo situaremos más adelante el estilo de vida de los albaicineros tradicionales.

2. Un modo posmaterialista, es el modo propio de una sociedad rica, caracterizada por la presencia de numerosas fuentes de satisfacción al mismo tiempo. Los recursos no son infinitos, pero son suficientes para que el sello de la calidad esté presente en la mayoría de las acciones de la vida cotidiana, incluyendo la vida laboral (Bauman, 1999), de manera que las tensiones están motivadas porque una parte resta satisfacción al bienestar conjunto que proporcionan los demás elementos en la vida del agente. Es el modo de las nuevas clases medias o la burguesía posmaterialista (Featherstone, 1991), para quienes la dimensión estética juega un papel cada vez más importante (Beck, Giddens y Lash, 2001).

\section{El Albaicín como espacio vital}

El Albaicín es un barrio de 101 hectáreas (espacio delimitado por un plan especial urbanístico propio), que constituye el núcleo histórico de la ciudad de Granada, aunque no su centro geográfico, pues su situación en una colina frente a la Alhambra lo dejó al margen del crecimiento y las distintas políticas y etapas desarrollistas del siglo recién terminado. Existen dos murallas árabes, además de numerosos restos, sobre todo en casas particulares, muchas iglesias y numerosas casas señoriales de los siglos XVI al XVIII. También conserva la red viaria casi intacta. En 1994 fue declarado Patrimonio de la Humanidad por la UNESCO.

El barrio perdió gran parte de su población durante los años 60 y 70 (Bosque Maurel, 1991), aunque actualmente parece haberse estabilizado. En abril de 
2000, era de 8.997 personas y suponía menos del 4\% de la población de la ciudad de Granada (252.593). Una de sus características principales es la gran diferenciación interna: zonas muy antiguas y otras zonas construidas en este siglo; zonas de cármenes (casa típica con jardín), zonas de pequeñas casas adosadas y zonas de bloques (de los siglos XIX y XX); zonas señoriales y zonas de miseria; zonas muy deterioradas y otras con muchas rehabilitaciones; zonas de gran riqueza patrimonial y otras con valor nulo; zonas de cuesta, zonas de vaguada, zonas llanas; zonas donde más del $30 \%$ de la población tiene más de 65 años y zonas donde ésta no llega al 15\% (De Pablos, Bernués y Cabrera, 2000).

De sus seis mil viviendas, hay muchas desocupadas y en mal estado de conservación, pero en los últimos años se vienen concediendo una media de cincuenta nuevas licencias de nueva ocupación y son casi mil las licencias de obra menor dedicadas a restauraciones parciales. Los regímenes de propiedad y alquiler se reparten equitativamente, pero lo más llamativo es que los precios más recientes de una y otro pueden equipararse a los de la mejor zona céntrica de Granada, lo que pone de relieve la atracción que está sufriendo el barrio por parte de los nuevos pobladores - proceso de gentrificación (Amendola, 2000) - y deja advertir algunas de las tendencias transformadoras presentes en él. También convendría señalar el carácter patrimonialista de la cultura granadina, que lleva a invertir en viviendas, así como hacer de la propia casa el centro de la existencia (Conde, 1999). Por otra parte, el barrio sufre los procesos propios de un centro histórico: integración funcional, especialización en hostelería, servicios culturales y profesionales, llegada masiva de turistas que recorren algunas calles y miradores y disfrutan del ambiente, sin duda lo más atractivo del Albaicín.

En cuanto a los estilos de vida, a continuación ofrecemos una caracterización de los dos mayoritarios que se han tenido en cuenta - descartándose los vinculados al islam, fragmentados y poco integrados, aunque dan una nota de originalidad, y los estudiantes, que constituyen una cierta masa de población flotante. No se ha pretendido estudiar grupos sociales, que pueden presentarse bajo diversas formas de estilos de vida, o al revés: un estilo de vida agrupar a miembros de diversos grupos (tal como sucede con la minoría gitana, bastante integrada en el estilo más tradicional del barrio). A continuación presentamos algunas características generales de dos de los estilos de vida estudiados:

1. El albaicinero tradicional: buena parte de los residentes en el Albaicín presentan una caracterización anclada en patrones tradicionales, correspondientes a esquemas de clase social media-baja, conforme a la tradición obrera del barrio. Muchas veces estrechos de miras y poco emprendedores, los albaicineros tradicionales han constituido la pieza clave en la transmisión del barrio y han sabido mantener el sabor y el ambiente que constituye la clave del Albaicín. Los viejos albaicineros no constituyen sin embargo un grupo homogéneo. En términos de calidad de vida, su realidad podría 
expresarse según lo que hemos denominado modo materialista, caracterizado principalmente por un carácter moderado del ingreso y los recursos materiales (De Pablos, Gómez y Pacual, 1999).

2. El nuevo poblador, que llega al Albaicín como consecuencia de su ascenso social. Con una buena situación profesional, este estilo de vida se da en los estratos medios y altos de la sociedad. Sus seguidores compran y rehabilitan antiguas viviendas, buscando unas condiciones de calidad de vida marcadas por la riqueza patrimonial, histórica y estética que sólo el Albaicín puede proporcionar, aun a costa de las privaciones que vivir en el barrio lleva consigo. Suele trabajar fuera del barrio, pero está dispuesto a invertir en su casa y hacer de ella el paraíso que compense otras dificultades. Podrían incluirse aquí los extranjeros fascinados por el Albaicín, que son una minoría que se deja notar. En cuanto a calidad de vida, se regirían por el modo posmaterialista, en el que la causa de las tensiones es la abundancia de opciones que se presentan ante ellos, más que el énfasis en los recursos, mucho más abundantes que en el grupo anterior.

Así, en un contexto de desigualdad social y de diferentes niveles de vida material, en el Albaicín han venido a confluir distintas prácticas culturales y económicas como consecuencia de la coexistencia de diferentes estilos de vida (prácticas que acabarán por transformarlo, pues cada estilo de vida recrea el barrio de manera diferenciada). De ahí que resulte significativo el estudio de la calidad de vida en un barrio caracterizado por la diversidad y la heterogeneidad, tanto sociocultural como de función social de los espacios o lugares funcionales entendidos, en términos de Maier (1987), como espacios destinados a funciones sociales concretas como el ocio, el trabajo, la residencia, el abastecimiento, la educación, etc.

En este sentido, el Albaicín ofrece en grado desigual la capacidad de satisfacer las necesidades de sus residentes, que también pueden ser diferentes. Primero, porque mucha gente de pocos recursos económicos no necesita más para vivir con calidad de vida. El modo materialista no es más que un nombre para expresar una forma de llevar a cabo la búsqueda de la calidad de vida, y quienes se encuentran en él no carecen de bienestar, sólo que éste se realiza de otra forma. De hecho, al lograrse la calidad en interacción con el medio, puede no ser difícil tenerla en el Albaicín para quien ha vivido siempre en él, con su favorable ambiente natural y sus redes sociales establecidas, que compensen las carencias materiales. Tan sólo —y aquí surge una línea de fractura- quienes no pueden contar con lo más básico en su vida, quienes carecen de actividades satisfactorias de cualquier tipo $-\mathrm{y}$ sobre todo, de lazos sociales, frecuente en personas mayores-, carecen de bienestar.

Por otro lado, vivir en el Albaicín para quienes se desenvuelven en el modo posmaterialista conlleva una gran cantidad de ventajas: el Albaicín proporciona la posibilidad de consumir un entorno privilegiado: casas con jardines y flores, luz, vistas a la Alhambra, patrimonio, aire fresco, etc. Aunque también comporta inconvenientes: dificultades e incomodidad en los accesos, insufi- 
ciencia de servicios, imposibilidad de construir o modificar la vivienda libremente, entre otros. En cualquier caso, a pesar de lo que pueda considerarse privilegio o no, cada colectivo se vincula con el Albaicín al identificar en él aspectos asociados a su calidad de vida, estableciendo así la especial significación que supone todo espacio habitado.

\section{Metodología}

El estudio, centrado en la participación de los agentes, se ha desarrollado con una metodología cualitativa, con la asunción de que nadie conoce mejor su realidad que quien la vive. Se ha utilizado la técnica de los grupos de discusión, debido a la riqueza de la información que se genera. Según Alonso (1998), los grupos de discusión no proporcionan conocimiento sobre el comportamiento, sino sobre los sistemas de representaciones sobre los objetos de estudio que sirven de base a los agentes para interpretar la realidad y actúan como esquemas generales del comportamiento. Mediante esta técnica, aplicada a grupos más o menos homogéneos, surge un debate orientado a la producción de discursos: se trata, por tanto, de un conjunto de procesos para la homogeneización de imágenes y expresiones, tomadas a partir de las variables establecidas como más significativas, esto es los estilos de vida concretados en la búsqueda diferenciada de la calidad de vida.

En nuestro estudio no interesan tanto los estilos de vida como procesos de identidad personal, sino como procesos sociales de construcción de la realidad, a través de las significaciones sociales. El proceso grupal por el que se obtienen las representaciones sociales sobrepasan la respuesta individual para lograr introducirnos en el universo simbólico del grupo de referencia, como resultado de la interacción de los diferentes agentes. La fertilidad de la aplicación de esta técnica de análisis de la realidad radica en que nos permite determinar los diferentes discursos generados a partir de las condiciones sociales de existencia (conflictos, cambios, tradiciones, historia...) que el investigador controla con la finalidad de reconstruir y modelizar las categorías que constituyen las representaciones desde las cuales los agentes dan sentido a la información que reciben y significado a las acciones que realizan (Delgado y Gutiérrez, 1994).

Al considerar la extensión poblacional del Albaicín, el estudio se desarrolló resaltando primeramente la disposición de participación de sus habitantes y luego, los criterios de inclusión establecidos previamente: se consideró como criterio la pertenencia a dos de los diferentes estilos de vida que configuran el barrio, el poblador originario o albaicinero tradicional, que sería el que habita en el barrio desde más de una generación y el nuevo poblador, perteneciente a la nueva burguesía posmaterialista, definido por aquéllos con menos de quince años que habitan el barrio. El estudio exploratorio se realizó con cinco grupos de discusión, donde tres grupos pertenecían al estilo de vida de los «albaicineros tradicionales» (en adelante, AT) y dos grupos pertenecían al estilo de vida «nuevo poblador» (en adelante, NP). Los grupos de los albaicineros tra- 
dicionales estuvieron constituidos por hombres y mujeres con edades comprendidas entre cincuenta y sesenta y siete años de edad, donde las mujeres desempeñan su tarea como amas de casa y los hombres son pensionistas. Los nuevos pobladores fueron hombres y mujeres con edades entre veintisiete y cuarenta y cinco años, con formación universitaria.

\section{Resultados}

\subsection{Significado de vivir en el Albaicín}

El espacio urbano es el producto sedimentado de intencionalidades múltiples, concurrentes o sucesivas, es la historia acumulada y reinterpretada. Indudablemente, en la medida en que éste es un espacio compartido de la vida, es un lugar objeto de confrontación que estructura de múltiples maneras las relaciones entre los ciudadanos, las instituciones y los grupos sociales (Grafmeyer, 1999). El espacio habitado tiene una particular significación en la vida individual, porque en él se condensan los elementos que recrean la existencia humana y se ubican aspectos con los cuales los individuos se identifican o bien poseen una representación que les enlaza con el grupo social. Como señala Remy (1999), el barrio viene a ser ese espacio urbano constituido por una red de objetos que delimitan escenas múltiples dentro de las cuales se desarrolla la vida social. El barrio representa, entonces, un espacio donde los individuos construyen y comparten experiencias, articulan valores y experimentan la diversidad: sigue siendo la "unidad mínima de apropiación social y perceptiva» (Hernández Aja, 2000: 86).

Vivir en el Albaicín tiene un significado diferente para los albaicineros tradicionales y para los nuevos pobladores, porque valoran aspectos distintos del mismo. Sin embargo, encontramos como invariante que vivir en el barrio no responde al azar sino a una intencionalidad, a una decisión voluntaria: frente a opciones que ofrecen otras condiciones, prevalece la valoración subjetiva que se le da al entorno. Los nuevos pobladores, poseedores de recursos para comprar en otras zonas, han decidido invertir allí; para los albaicineros tradicionales - que se quedaron a pesar del éxodo de los años sesenta y setenta-, las posibilidades actuales de salir son la venta de sus casas y los ofrecimientos de los hijos de mudarse a un piso más confortable:

Es mi vida, yo no podría vivir fuera de aquí. (Mujer AT)

A mí me han venido a comprá mi casa y yo les digo la casa no está en venta... Yo no cambio esto por ná. (Hombre AT)

Mis hijas se casaron y se fueron porque no pudieron comprar aquí y me tienen una habitación en su casa para que nos vayamos, pero ni mi marido ni yo nos movemos de aquí. Aquí está mi gente. (Mujer AT)

Vivir en el Albaicín significa únicamente vivir en un entorno histórico, no hay comercios especializados, no creo que el barrio cumpla las necesidades que tenemos. (Mujer NP) 
Para mí sí hay calidad de vida, mucho más que en otros barrios, porque a mí me gusta oír los pajarillos, salir... Yo me encuentro aquí muy a gusto porque es un pequeño pueblo que a la vez está en la ciudad. No me gustaría vivir en un pueblo que no estoy acostumbrada y sin embargo aquí tengo cerca la ciudad. Claro, depende de lo que esperes y de lo que te guste y espero que haya cosas que mejoren. (Mujer NP)

Frente a la identidad por adscripción del albaicinero tradicional $-\mathrm{y}$ a la que no se está dispuesto a renunciar en absoluto-, encontramos la identidad por elección del nuevo poblador. Con todo, los criterios de ambos grupos son distintos, tanto por lo que se refiere al proyecto personal, como por un cierto sentido utilitario que los nuevos pobladores otorgan al entorno, como elemento de distinción social. Por otra parte, es posible también que la revalorización material y simbólica del Albaicín influya en la reinterpretación de los albaicineros tradicionales de su propia calidad de vida, pues la conciencia de prestigio y reconocimiento social les otorga un nuevo estatus ante la sociedad, con la consiguiente mejora en bienestar (Requena Santos, 2000).

\subsection{Comunidad y vida familiar}

La comunidad aporta apoyo, seguridad, solidaridad, integración, identidad y sentido de pertenencia social; es un entorno humano donde la virtud tiene un atributo social y donde, por tanto, existe una conciencia moral compartida (Etzioni, 1999). Por su parte, la familia es ese espacio privilegiado de relaciones próximas, donde se experimentan sentimientos, necesidades, expectativas, deseos, percepciones externas e internas, delimitado frente a un mundo exterior o respecto a necesidades y exigencias de los demás (Barbagelata y Rodríguez, 1995: 51). Y por fin, en medio de las redes familiares y sociales, el vecino es considerado popularmente como un pariente cercano, de ahí su importancia al reconocerse como parte de una comunidad y de su percepción de calidad de vida. La relevancia de estos aspectos se manifiesta en las expresiones de los residentes:

Entre los que somos albaicineros de toa la vida hay mucha unión, nos ayudamos, somos amigos... (Mujer AT)

El Albaicín tiene un encanto para otro tipo de personas, por ejemplo, para mí [...] Yo tengo mi familia a 500 quilómetros de aquí, porque procedo de otro lugar, y para mí es importante estar en un sitio donde hay gente cercana y querida, donde puedas tener un espacio privado, pero que tengas una red personal y social propia, y el Albaicín eso lo facilita. (Mujer NP)

Aquí te puedes sentir acompañado, teniendo también tu espacio privado para cuando quieras. (Mujer NP).

Los albaicineros tradicionales otorgan una importancia significativa a la existencia comunitaria, expresada en una fuerte convivencia con el vecino, visto como parte fundamental e indispensable en sus vidas. Sin embargo, al 
referirse a la familia, se expresaba la dificultad de la forzada emigración de los hijos. Por su parte, los nuevos pobladores también consideran importante la convivencia y la participación en la vida de la comunidad, produciéndose un fenómeno de identificación con ella, aunque igualmente se advierten diferencias en la forma en que la comunidad está presente en su vida, particularmente expresada en el deseo de conservar su privacidad.

\subsection{Confort físico-ambiental}

La consideración de este aspecto en el estudio de la calidad de vida en un barrio tiene particular importancia dadas las peculiares características físico-ambientales del Albaicín. Tomamos de Setién (1993: 313) la comprensión de este aspecto en su doble dimensión —objetiva y subjetiva- que contempla el entorno natural y su relación con el hombre (aire, agua, suelo) y el medio material y social creado por el hombre (vivienda, barrio, comunidad). Es obligado contemplar aspectos como los elementos ambientales relacionados con el recreo (parques, jardines, instalaciones deportivas), las condiciones físicas (ruido, hacinamiento, barreras arquitectónicas) y la existencia de guetos en donde se concentran problemas de delincuencia, marginalidad, pobreza o prostitución, que se convierten en factores ambientales de estrés. En general, estos factores son susceptibles de ser percibidos de manera inmediata por los habitantes del barrio, constituyéndose en elementos que afectan o favorecen su calidad de vida, dado que conforman su medioambiente entendido como el resultado de «la relación del individuo, la comunidad y la sociedad con el entorno físico donde se asientan y donde habitan» (Tejero, 1997: 193).

En el Albaicín se identifica lo que otorga o no confort con lo concerniente a comodidades en el barrio, los servicios con que se cuenta (tanto públicos como privados), la facilidad de acceso vial y la calidad del ambiente. Sin embargo, la percepción diferenciada de estos elementos viene a mostrar la relevancia entre los dos modos de entender la calidad de vida que venimos manejando. En primer lugar, para algunos de sus habitantes, de pocos recursos económicos, no se necesita más de lo que se tiene actualmente para vivir con calidad de vida. Es el caso de los ubicados en el estilo de vida del modo materialista, que - recordamos de nuevo- es sólo un nombre para expresar una forma de llevar a cabo la búsqueda de la calidad de vida. Éstas son algunas de sus expresiones:

¿Calidad de vida? Para mí eso es vivir tranquilo y tener lo necesario. Tener pa' comer y pa' vivir, y que nadie se meta con nadie. (Hombre AT)

[...] todas las calles son típicas de piedra y mientras vas cumpliendo más años pues... te va molestando las piedras... (Mujer AT)

Hay que destacar de nuevo la relevancia de los aspectos sociales, así como la favorable interacción con el medio, como sucede a quien ha vivido siempre 
en el Albaicín, con su ambiente natural y social y sus redes sociales establecidas, que compensan carencias materiales, aunque algunas se dejen sentir. Desde luego, si su referente de bienestar es el barrio en el pasado (Navarro y Pérez Yruela, 2000), no es de extrañar esta respuesta, pues el Albaicín ha mejorado notablemente sus infraestructuras y comunicaciones. Por el contrario, los nuevos pobladores se muestran mucho más críticos con el barrio:

No hay grandes espacios comerciales, sino que te acostumbras a volver a comprar en la pescadería, en la carnicería... Mucho contacto de barrio, de la gente, aquí entras a una tienda y te puedes encontrar... Todo el mundo se conoce. (Mujer NP)

Los comercios de la zona, lo siento muchísimo por ellos pero no me dan el servicio que yo necesito. (Mujer NP)

\subsection{Ocio y tiempo libre}

El ocio y el tiempo libre se han constituido en indicadores significativos de calidad de vida. Para Cuenca (1999: 24), el ocio es considerado como un espacio vital al que todos tenemos derecho y cuya apropiada conducción favorece, entre otros aspectos, la salud, el encuentro social, el desarrollo y la integración. En el estilo de vida posmaterialista, de los nuevos pobladores, esta dimensión tiene una connotación asociada con espacios e infraestructuras variadas, donde se puedan realizar prácticas recreativas de diversa índole. Se descubre la tensión entre la carencia de equipamientos colectivos y las posibilidades de la vida individual:

Si hablamos de infraestructura de ocio según lo que hoy debe de entenderse como unos equipamientos de ocio, no hay ningún tipo de equipamientos culturales para un barrio que parece una ciudadela del siglo XVIII: no hay teatros, lugares para jugar a la petanca, es decir no hay ni culturales ni sociales... Desde el punto de vista de equipamientos del ocio, cero. (Hombre NP)

Con respecto al ocio cotidiano, creo que sí existe; digamos que para una ama de casa, aunque trabajemos, cuando llegas a tu casa, casi todo el mundo tiene una terraza o un pequeño patio y eso te puede servir de relax. Pero lo que es el ocio social de eso no hay nada. (Mujer NP)

Para el estilo de vida de los albaicineros tradicionales, la clave se halla en la posibilidad de disfrute de sus plazas, de sus miradores, jardines en el interior de las casas y de las charlas con los vecinos; compartiendo más su entorno, en continuidad con lo anterior:

Aquí no hay parque pa' los niños, ni hay pa' los ancianos, aquí arriba no hay un sitio donde ir. (Mujer AT)

Aquí las casas en su mayoría tienen su patio, su huerta... Otras, un pequeño jardincillo... Entonces, aquí se hace la vida. (Mujer AT) 
Mi jardín... Mis nietos disfrutan de todo esto... Los pajaritos por las mañanas [...] Aquí nos reunimos todas las amigas por las tardes para tomar la merienda. Eso no lo tendré en ninguna parte. (Mujer AT)

A pesar de las diferencias en la percepción que se tiene del ocio y el tiempo libre desde cada estilo de vida, para ambos grupos esta dimensión está medianamente satisfecha en el barrio por el disfrute de sus condiciones ambientales y de las características particulares de sus viviendas. Además, observamos el interés común por que en el barrio se rescaten los espacios públicos, miradores y plazas como lugares para el esparcimiento y la recreación de los pobladores. Este interés, que refuerza el sentido de identidad e implicación con el barrio y su comunidad, podría traducirse en una mayor colaboración y participación social por el bienestar colectivo y personal, tal como señala Vega (1998). Sin embargo, en seguida entrará en conflicto con uno de los temas más relevantes del barrio, considerado como recurso para el conjunto de la ciudad de Granada: el turismo.

\subsection{Actividad turística y vida en el Albaicín}

Mientras que el uso comercial —y sobre todo industrial — del barrio es relativamente escaso, el uso turístico se incrementa progresivamente: visitantes locales y foráneos disfrutan de su ambiente y sus posibilidades en restaurantes y terrazas, creando a veces conflictos con el uso residencial. A partir de los datos contenidos en una encuesta turística realizada en la Alhambra (Latiesa, 2000), puede estimarse la llegada de 980.000 turistas anuales al barrio, sin contar las visitas de los propios residentes de la ciudad. Mientras que la Alhambra representa un turismo de masas, estrictamente organizado, la situación relativa al Albaicín es muy distinta, pues, entrando de lleno en la categoría de turismo cultural (Ruiz Baudrihaye, 1997), el barrio es recorrido tanto por viajes organizados que llegan en autobús a sus inmediaciones como por pequeños grupos de paseantes, que vienen a confluir en determinados lugares, como los miradores.

A pesar de las grandes cifras que mueve el turismo, sus consecuencias en las economías locales no son bien conocidas y presentan efectos contradictorios (Sinclair y otros, 1994). Esta realidad se refleja en las opiniones que poseen los residentes del Albaicín, acerca de su impacto en el barrio y su economía, y aunque la polarización no es completa, parece advertirse mayor tolerancia entre los albaicineros tradicionales, frente a la visión de los nuevos pobladores, para los que el turismo - o determinado tipo de turismo- podría ser considerado como un elemento perturbador y poco generador de beneficios:

El turismo es una forma de dar vida, porque entra un autocar y entran 50 personas a un café y son cincuenta cafés que se venden, si aquí no viene el turismo no se venden esos 50 cafés. (Hombre AT) 
Para mí lo positivo es que vienen y visitan el barrio; lo negativo es que antes tu te podías sentar en San Nicolás un rato y ahora llegas a San Nicolás y no te puedes ni sentar con un mundo de gente adelante... (Mujer AT)

Lo que más molesta en el barrio, los grandes grupos que pasan por las calles y sólo pasan y no ven nada, porque yo creo que es un tipo de turismo muy masificado y rápidamente pasan y... yo he oído quejas de gente. (Mujer NP)

A mí montones de personas me piden permiso para entrar en mi casa y verla. Esa gente no molesta, generalmente consumen en el barrio. Ahora, los grupos estos numerosos que no te dejan pasar, y que aparcan los autobuses con peligro de accidente y todo... Esta gente no te deja nada en el barrio, lo único que hace es molestar. (Mujer NP)

\subsection{Apoyo institucional}

La importancia de lo que ha de ser así al considerar las condiciones de calidad de vida es especialmente relevante en un contexto calificado como Patrimonio de la Humanidad, puesto que determinados criterios han de constituir la guía imprescindible para la revitalización del barrio. Las experiencias recogidas por Shackley (1998) destacan la relevancia de cuidar no sólo las condiciones del hábitat, sino también de proteger a la población autóctona del lugar.

Entre las críticas que la Administración pública ha recibido con respecto a su intervención en el barrio (Carrascosa, 2001), podría aceptarse su tardanza en la actuación y su manifiesta descoordinación. Pero desde luego, con Montabes (2001), habría que estar de acuerdo en que si la iniciativa pública no dinamiza, la sociedad granadina — por su propia cultura (Conde, 1999) - escasamente se moviliza. Aun así, a pesar de todo, el modus operandi final de la Administración puede resultar satisfactorio: tras una etapa en la que la intervención ha estado centrada en la rehabilitación de espacios públicos y monumentos y el fomento de actividades económicas, en orden a la revitalización, toca el turno de la rehabilitación de viviendas. Aunque es un tema que siempre ha estado presente, la situación actual está marcada por la presencia de la Oficina Municipal para la Rehabilitación y de la Unidad Técnica del Albaicín, que ha consolidado su tarea como garante del ambiente del barrio, al revisar cualitativamente los proyectos. Como ya se ha dicho, el resultado de esta política, unida a la coyuntura favorable, es la enorme actividad constructora en el barrio, hasta el punto de que el interés de constructores y consumidores puede acabar constituyendo una amenaza real por su volumen.

Para los residentes, una vez mencionados los problemas con las infraestructuras, el problema se traduce ahora en los aspectos relacionados con la construcción y reconstrucción de las viviendas. Los albaicineros tradicionales no tienen nada fácil la rehabilitación y acondicionamiento de las viviendas, por la falta de recursos para proceder a hacer efectivo el proyecto de rehabilitación, así como la dificultad de acceso a la información y la complejidad de los trámites: 
Que los organismos den dinero a la gente que vive aquí para que puedan rehabilitar sus casas y quedarse a vivir en ellas y no se tengan que ir. Sus hijos aquí no han tenido donde vivir. (Mujer AT)

Una cierta vez dieron dinero para arreglar las viviendas, pero le dieron los dineros a quienes menos falta le hacen. (Hombre AT)

Le llevé los papeles de mi casa, que se caen las escaleras abajo y ni me han contestao. Han perdío los papeles y ni me han arreglao ná. (Hombre AT)

Para los nuevos pobladores, las normas de rehabilitación constituyen un factor que entorpece la libertad para remodelar las casas de acuerdo con exigencias personales de confort y espacio. Las expresiones siguientes lo reflejan:

El problema es que pedir subvenciones de rehabilitación es tener un técnico del Ayuntamiento en la puerta de tu casa, controlándote el proyecto. Es tener un técnico que no te va a permitir ni abrir las ventanas, ni poner ciertas cosas y te lo complica más. La gente no pide subvenciones y hace la obra el fin de semana y de pronto te la has encontrado hecha. (Mujer NP)

A mi me encantaría saber que tienes una oficina en el barrio a la que tu vas y le dices necesito hacer esto... Pero es ridículo el conservar un ladrillo... Vale, que está muy bien, pero no puedes obligar a alguien a desmontar toda la casa para salvar yo que sé, cien ladrillos... Porque no lo vas a hacer. (Mujer NP)

Desde cada estilo de vida, habitar cierto espacio va más allá de la simple posesión de un techo. Su integración en el barrio orienta su interés porque éste adquiera las condiciones que, de acuerdo con su estilo de vida, resultan indispensables para gozar de calidad de vida. Esta importancia del espacio habitado viene a concretarse en que las acciones individuales de sus habitantes se traducen en factores de crecimiento y desarrollo del mismo.

\subsection{Contribución individual y colectiva al desarrollo del barrio}

La construcción de la ciudad es un tema de interés creciente, asociado al protagonismo que las ciudades están llamadas a desempeñar en un sociedad globalizada (Castells, 1998). Autores como Ruiz Ballesteros (2000) han estudiado el tema desde la iniciativa pública, referido a la dimensión simbólica de la ciudad. Por su parte, Alguacil (2000) ha tratado nuevas formas de organización grupal, vinculadas al tercer sector. Mucho más modestamente, en este trabajo se han explorado algunas repercusiones de los estilos de vida, aplicados a un campo más reducido, como es el ámbito del barrio. Sin embargo, se proporcionan evidencias de cómo las relaciones significativas -en busca de la calidad de vida - generan nuevas prácticas sociales urbanas diferenciadas, en orden a la reproducción de la sociedad. Dado que la dualidad objetivo-subjetivo impregna la acción social, nos pareció relevante preguntar a los participantes en los grupos de discusión acerca de la conciencia de 
su contribución al barrio: si cada estilo de vida dirige acciones orientadas a mantener el espacio habitado, ¿en qué medida existe una conciencia de la aportación o transformación del barrio? Y como antes, nuevamente hemos encontrado un conjunto de respuestas que permiten discernir la práctica diferenciada en la construcción de la ciudad, a partir del sentido de la propia actuación.

Para los nuevos pobladores, la percepción de su contribución al barrio está referida a la inversión hecha en equipamiento, compra de la vivienda y a la integración con la gente del barrio:

Yo le aporto al barrio mucho dinero y jno me dejan coger el coche! He tenido que hacer una obra en mi casa y ${ }_{i}$ he desistido de hacerlo porque me cobran mucho! Ya en serio, me he integrado mucho en el barrio, he sido de la asociación, mi hija ha ido a este colegio y pienso que no he aportado menos de lo que pueda hacer otra persona del barrio. (Mujer NP)

Procuro ser buena vecina e intento vivir del barrio, consumir servicios de aquí. (Mujer NP)

Esta dimensión fue percibida por los albaicineros tradicionales más con un criterio emotivo que práctico, manifestándose cierto recelo respecto a lo que los nuevos pobladores puedan sentir y hacer por el barrio y su arquitectura. De allí que su contribución al desarrollo del barrio quede expresada de la siguiente manera:

Aquí nosotras compramos en el barrio. (Mujer AT)

Lo que hacemos lo hacemos respetando lo que el barrio necesita y como lo que es. Pero las personas que vienen de afuera... Ellos hacen unas grandezas de casas... (Mujer AT)

Nosotras cuidamos de nuestro barrio, aquí nosotras nos preocupamos por mantener limpia la calle. (Mujer AT)

La vida del barrio somos nosotras, las amas de casa. (Mujer AT)

Esta última expresión es singularmente significativa, y resume de alguna manera el conjunto de diferencias existente entre los antiguos y nuevos pobladores: mientras que para éstos el barrio es el lugar en el que se vive, que ofrece más o menos y al que se le dedica más o menos, los albaicineros de siempre son el barrio.

\section{Conclusiones}

En el cuadro 1 se ofrece un resumen donde se recoge la visión de los habitantes con relación a cada uno de los aspectos sondeados, a partir de los grupos de discusión estudiados. 
Cuadro 1. Estilos y calidad de vida en el espacio habitado.

\begin{tabular}{|c|c|c|}
\hline $\begin{array}{l}\text { Aspectos del espacio } \\
\text { habitado asociados } \\
\text { a la calidad de vida }\end{array}$ & $\begin{array}{l}\text { Albaicineros } \\
\text { tradicionales }\end{array}$ & $\begin{array}{l}\text { Nuevos pobladores, } \\
\text { burguesía posmaterialista }\end{array}$ \\
\hline $\begin{array}{l}\text { Significado de vivir } \\
\text { en el barrio }\end{array}$ & $\begin{array}{l}\text { Espacio asociado a la vida } \\
\text { afectiva y de relaciones. } \\
\text { Historia familiar, cultural } \\
\text { y condiciones ambientales } \\
\text { generan lazos para decidir } \\
\text { quedarse a vivir en él. }\end{array}$ & $\begin{array}{l}\text { Espacio exclusivo y privilegiado, } \\
\text { Patrimonio de la Humanidad. } \\
\text { Lugar escogido para vivir } \\
\text { por sus características. }\end{array}$ \\
\hline $\begin{array}{l}\text { Convivencia en la comunidad } \\
\text { y vida familiar }\end{array}$ & $\begin{array}{l}\text { Indispensable para el apoyo } \\
\text { dentro del entorno personal. } \\
\text { La familia se entiende en sentido } \\
\text { extensivo a los vecinos. } \\
\text { Las meriendas y tertulias } \\
\text { en casa de los vecinos son } \\
\text { muy importantes. }\end{array}$ & $\begin{array}{l}\text { Permite mantener relaciones } \\
\text { con los vecinos conservando } \\
\text { la privacidad. }\end{array}$ \\
\hline $\begin{array}{l}\text { Confortabilidad física } \\
\text { y ambiental }\end{array}$ & $\begin{array}{l}\text { El confort no se asocia con } \\
\text { la abundancia de recursos, } \\
\text { sino con el disfrute de la } \\
\text { naturaleza y las relaciones } \\
\text { sociales. }\end{array}$ & $\begin{array}{l}\text { Está asociada a un entorno } \\
\text { privilegiado por sus } \\
\text { condiciones ambientales } \\
\text { y con una buena dotación } \\
\text { de servicios públicos y privados } \\
\text { (espacios de consumo). }\end{array}$ \\
\hline Ocio y tiempo libre & $\begin{array}{l}\text { Compartir lugares privados } \\
\text { o públicos, tales como calles, } \\
\text { plazas y jardines. }\end{array}$ & $\begin{array}{l}\text { Disfrutar de espacios } \\
\text { e infraestructuras diversas } \\
\text { para prácticas recreativas. }\end{array}$ \\
\hline Actividad turística en el barrio & $\begin{array}{l}\text { Revitaliza el barrio y estimula } \\
\text { la actividad comercial. }\end{array}$ & $\begin{array}{l}\text { Elemento perturbador } \\
\text { de la tranquilidad. Invade } \\
\text { la privacidad y aporta pocos } \\
\text { beneficios al barrio. }\end{array}$ \\
\hline Apoyo institucional & $\begin{array}{l}\text { Es importante y necesario para } \\
\text { la conservación del barrio, } \\
\text { aunque no sean suficientes } \\
\text { los aportes financieros. }\end{array}$ & $\begin{array}{l}\text { Desde la perspectiva de la } \\
\text { vivienda, es un factor que } \\
\text { entorpece la libertad de } \\
\text { confort y uso de los espacios. }\end{array}$ \\
\hline $\begin{array}{l}\text { Contribución individual } \\
\text { y colectiva al desarrollo } \\
\text { del barrio }\end{array}$ & $\begin{array}{l}\text { Cuidar y mantener el ambiente } \\
\text { y las viviendas, de acuerdo } \\
\text { con las tradiciones y con las } \\
\text { reglamentaciones. }\end{array}$ & $\begin{array}{l}\text { Inversión de los recursos propios } \\
\text { en equipamiento y rehabilitación } \\
\text { de viviendas. Participación } \\
\text { en las asociaciones de vecinos. }\end{array}$ \\
\hline
\end{tabular}

En 1974, Ledrut se mostraba pesimista con respecto a la vida en los barrios, minimizados entre los dos polos que rigen la vida de sus residentes en el mundo actual: la ciudad y la vivienda: "La realidad del barrio carece de solidez. No existe "comunidad local" de barrio. La significación de éste tiende a hacerse instrumental y mecánica» (Ledrut, 1974: 207). Los hallazgos de este trabajo no permiten darle la razón, aunque tampoco se la quitan por completo. Veamos de qué manera tiene esto lugar. 
El Albaicín es un entorno singular, dotado de una estructura peculiar y de una fuerte significación simbólica, como núcleo histórico de la ciudad de Granada. Todo el foco del trabajo ha estado constituido por la relación con este entorno característico, que ha sido el prisma a través del cual hemos tratado de ver cómo dos estilos de vida diferentes configuran sus prácticas cotidianas de calidad de vida, para acabar volviendo sobre el propio barrio. En ese sentido, hay que reconocer que - al menos para un barrio histórico- el entorno, los edificios, el ambiente continúan actuando "como productores, reproductores y soportes de cultura y de memoria» (Bouzada Fernández, 2001: 66). Desde esa perspectiva, consideramos que la situación analizada en este trabajo tiene muchos rasgos generalizables a otros contextos similares, tanto por las condiciones equivalentes de muchos centros históricos como por su relación con la reproducción de la ciudad.

Desde luego, el barrio ofrece espacio y condiciones objetivas suficientes para ofrecer calidad de vida a sus residentes, satisfaciendo de manera diferenciada sus necesidades diferentes, expresadas a través de los requerimientos manifestados. De esta manera, el Albaicín se vuelve significativo para cada estilo de vida estudiado. A pesar de las discrepancias entre ambos estilos, existe en ellos un profundo interés por la conservación de las características culturales y sociales del Albaicín. Los estilos estudiados no son opuestos, pero tampoco son convergentes, y la posible complementación actual puede verse alterada en el futuro con la desaparición estructural de los albaicineros tradicionales, dada la imposibilidad económica de que sus hijos permanezcan en el barrio.

El peso del entorno es mucho mayor en el caso de los albaicineros tradicionales, para quienes las relaciones sociales y las prácticas de convivencia les llevan a advertir que son el alma del barrio. Los nuevos pobladores desean los lazos comunitarios, pero éstos tienen el contrapeso de una vida privada que no se limita al ámbito del barrio, pues se extiende hacia dentro y hacia fuera, con exigencias que suponen una novedad para la vida del Albaicín. Los nuevos pobladores son capaces de pensar con sentido mucho más crítico, al que unen el sentido instrumental del que hablaba Ledrut: la medida de su calidad de vida es su propio bienestar, determinado en parte por patrones ajenos a la tradición del barrio y en parte por aquéllos específicos que ofrece el Albaicín.

Los albaicineros tradicionales han representado la continuidad del Albaicín hasta hoy, pero su situación —aunque satisfactoria en términos de calidad de vida - no es fácil, dado lo limitado de sus recursos. Los nuevos pobladores suponen una aportación imprescindible en población y en riqueza material. De esta manera, la tradición que supone el propio Albaicín no sólo se transmite a través del continuo trabajo de interpretación de la misma, como señala Giddens (Beck, Giddens y Lash, 2001: 84), sino del trabajo de reconstrucción del espacio, a través de las relaciones sociales de quienes lo habitan, aunque no de manera exclusiva: la capacidad de reconstruir el barrio con arreglo a los patrones ambientales característicos vendrá dada por el mercado, pero también por las autoridades urbanísticas de la ciudad, que pueden dejarse arrastrar por el desarrollismo. 
En cualquier caso, pautas más o menos tradicionales, de carácter comunitario, pueden acabar modificándose. En este sentido, el uso residencial del barrio puede convertirlo en la urbanización Albaicín. Y en cualquier caso, ser una fuente de conflictos, ya que el barrio es un recurso específico de Granada: un lugar funcional turístico, así como de ocio y hostelería para los habitantes de la ciudad.

Se transformará la simbología del Albaicín: en su historia, el barrio seguirá siendo el resumen de las esencias de la ciudad de Granada, al menos mientras permanezca físicamente inalterado en líneas generales. Pero el casticismo de la tradición (González Alcantud, 1996), de Ganivet o de García Lorca, sin duda se verá modificado al compás de la sustitución de la población. De esta manera, el barrio, en gran parte premoderno hasta bien entrado el siglo XX, se integrará plenamente - con sus ventajes e inconvenientes - en la modernidad.

\section{Bibliografía}

AlguaCIL, J. (2000). Calidad de vida y praxis urbana. Madrid: CIS-Siglo XXI.

Alonso, L.E. (1998). La mirada cualitativa en sociología. Madrid: Fundamentos. Amendola, G. (2000). La ciudad postmoderna. Madrid: Celeste Ediciones.

ANDER-EGG, E. (1998). Metodología y práctica del desarrollo comunitario. V.1, ¿Qué es el desarrollo de la comunidad? Buenos Aires: Lumen-Humanitas.

Andrés Orizo, F. (1992). «La sociedad de bienestar». En Miguel, A. de. La sociedad española 1992-1993. Madrid: Alianza.

BARBAGELATA, N.; RodríGUEZ, A. (1995). «Estructura familiar e identidad». Revista de Estudios Sociales y de Sociología Aplicada, 98, p. 49-59.

BAUMAN, Z. (1999). Trabajo, consumismo y nuevos pobres. Barcelona: Gedisa.

BECK, U. (2001). «Vivir nuestra propia vida en un mundo desbocado: individuación, globalización y política». En Giddens, A.; HuTTON, W. (eds.). En el límite. La vida en el capitalismo global. Barcelona: Tusquets.

BECK, U.; GIDDENS, A.; LASH, S. (2001). Modernización reflexiva: política, tradición y estética en el orden social moderno. Madrid: Alianza.

Bocock, R. (1995). El consumo. Madrid: Talasa.

Bosque Maurel, J. (1991). Atlas social de la ciudad de Granada. Granada: Caja General de Ahorros.

Bourdieu, P. (1991). La distinción. Madrid: Taurus.

BouZADA FERnÁndeZ, X. (2001). «Los espacios culturales del consumo cultural colectivo». Revista Española de Investigaciones Sociológicas, 96, p. 51-70.

CAmpbell, A.; CONVERSE, PH.; RODGERS, W. (1976). The Quality of American Life. Perceptions, Evaluations and Satisfactions. Nueva York: Russel Sage Foundation.

Carrascosa Salas, M. (2001). El Albaicín en la historia (I). Granada: Proyecto Sur.

CASTELLS, M. (1998). El poder de la identidad. La era de la información. Vol. 2. Madrid: Alianza.

CONDE, F. (1999). Urbanismo y ciudad en la aglomeración de Granada. Cultura e identidades urbanas. Sevilla: Consejería de Obras Públicas y Transportes.

CuENCA, M. (1999). Ocio y formación. Hacia la equiparación de oportunidades mediante la Educación de Ocio. Documentos de estudios de ocio, 7. Bilbao: Universidad Deusto. 
Delgado, J.M.; GuTIÉRreZ, J. (1994). Métodos y técnicas cualitativas en ciencias sociales. Madrid: Síntesis.

Etzioni, A. (1999). La nueva regla de oro. Comunidad y moralidad en una sociedad democrática. Barcelona: Paidós.

Featherstone, M. (1991). Consumer Culture and Post-modernism. Londres: Sage. GIDDENS, A. (1995). Modernidad e identidad del yo. El yo y la sociedad en la época contemporánea. Barcelona: Península.

GonZÁlez AlCANTUd, J.A. (1996). «Estudio preliminar». En Gil BenumeYA, R. Ni oriente ni occidente. El Universo visto desde el Albayzin. Edición facsímil. Prólogo de Rodolfo Gil Grimau. Granada: Universidad de Granada.

GONZÁLEZ GARCÍA, I. (2000). «La variedad urbana: una condición necesaria para la calidad de vida en modernidad». Documentación Social, 119, p. 115-136.

GRAFMEYER, Y. (1999). "La coexistence en milieu urbain: échanges, conflits, transaction». Recherches Sociologiques, 1, p. 157-176.

Hernánez AjA, A. (2000). "Barrio y equipamiento público, esencia del proyecto democrático de la ciudad». Documentación Social, 119, p. 79-93.

INGLEHART, R. (1991). El cambio cultural en las sociedades industriales avanzadas. Madrid: CIS-Siglo XXI.

LATIESA, M. (2000). Granada y el turismo. Análisis sociológico, planificación y desarrollo del Proyecto Europeo Pass-Enger. Granada: Universidad de Granada.

LEDRUT, R. (1974). El espacio social de la ciudad. Buenos Aires: Amorrortu.

LEONARDO AURTENETXE, J. J. (1989). Estructura urbana y diferenciación residencial: el caso de Bilbao. Madrid: CIS-Siglo XXI.

MAfFesoli, M. (1990). El tiempo de las tribus. Barcelona: Icaria.

MAIER, J. y otros (1987). Geografía social. Madrid: Rialp.

Michalos, A. (1985). "Multiple discrepancies theory (MDT)». Social Indicators Research, 16 (4), p. 347-413.

Montabes Pereira, J. (2001). "Granada y los granadinos entre el chavico y el euro». Diario Ideal, 12 de junio de 2001. Suplemento especial «El futuro económico y empresarial de Granada», p. 42-43.

Navarro Yáñez, C.; Pérez Yruela, M. (2000). "Calidad de vida y cambio social. De la polarización social a la axiológica en la sociedad andaluza». Revista Internacional de Sociología, 26, p. 5-38.

Nordenfelt, L. (1993). Quality of Life, Health and Happiness. Aldershot: Avebury.

Nussbaum, M.; Sen, A. (comp.) (1996). La calidad de vida. México: FCE.

OCDE (1982). La liste OCDE des indicateurs sociaux. París: OCDE.

Pablos, J.C. de; Gómez, Y.; Pascual, N. (1999). "El dominio sobre lo cotidiano: la búsqueda de la calidad de vida». Revista Española de Investigaciones Sociológicas, 86, p. 55-78.

Pablos, J.C. de; Pascual, N.; Gómez, Y. (1999). La búsqueda de la calidad de vida: una aproximación interpretativa. Granada: Facultad de CCPP y Sociología.

Pablos, J.C de; BernuÉs, C.; CABrera, J. (2000). El Albaicín de Granada: Una aproximación sociológica. Informe de Investigación. Fundación Albaicín, Granada.

REMY, J. (1999). "La ville: architectonique spatiale et univers d'intercompréhension». Recherches sociologiques, 1, p. 177-183.

REQUENA SANTOS, F. (2000). «Satisfacción, bienestar y calidad de vida en el trabajo». Revista Española de Investigaciones Sociológicas, 92, p. 11-44.

Ruiz Ballesteros, E. (2000). Construcción simbólica de la ciudad. Madrid: Miño y Dávila. 
RUIZ BAUDRIHAYE, J.A. (1997). «El turismo cultural: luces y sombras». Estudios Turísticos, 134 , p. 43-54.

SEN, A. (1995). Nuevo examen de la desigualdad. Madrid: Alianza.

SETIÉN, M.L. (1993). Indicadores sociales de calidad de vida. Un sistema de medición aplicado al País Vasco. Madrid: CIS-Siglo XXI.

SHACKLEY, M. (ed.) (1998). Visitor Management. Case studies from World Heritage Sites. Oxford: Butterworth-Heinemann.

SINCLAIR, T. y otros (1994). «Estrategias de turismo metropolitano». Revista de Estudios Turísticos, 124, p. 15-30.

SOldeVIla PÉREz, C. (1998). Estilo de vida. Hacia una teoría psicosocial de la acción. Madrid: Entinema.

Tejero, E. (1997). «Hacia una sociedad ambiental». Papers, 51, p. 191-199.

Vega, M.T. (1998). «Perspectiva psicosocial del ocio». En GIL, F. y otros (coord.). Para comprender el Ocio. Estella (Navarra): Verbo Divino. 